\title{
ESTUDO DE PERCEPÇÕES QUANTO ÀS MELHORIAS ORIUNDAS DA IMPLANTAÇÃO E PRÁTICA DO GERENCIAMENTO DA ROTINA
}

\section{A STUDY ABOUT THE PERCEPTIONS OVER THE RESULTS FROM ROUTINE MANAGEMENT IMPLEMENTATION}

\author{
Priscila Nogueira ${ }^{1}$; Helder Gomes Costa ${ }^{2}$ \\ ${ }^{1}$ Programa em Sistemas de Gestão, Universidade Federal Fluminense - UFF - Niterói - Brasil - \\ pnogueira@sustentabile.com.br \\ ${ }^{2}$ Programa em Sistemas de Gestão, Universidade Federal Fluminense - UFF - Niterói - Brasil - \\ hgc@pq.cnpq.br
}

\begin{abstract}
Resumo
Diversas fontes bibliográficas apregoam que o emprego de técnicas de gerenciamento da rotina como método para a melhoria contínua no gerenciamento de operações possibilita a essas organizações avaliar e ajustar seus processos internos e seus custos, aumentando o valor agregado do serviço prestado e atingindo novos e melhores patamares de competitividade. Apesar desta crença, não foi identificado na literatura experimento que capte a percepção do impacto da aplicação desta técnica nos processos organizacionais. O presente trabalho objetiva captar a percepção de gestores e empregados sobre os impactos em processos e no conhecimento, causados pela da implantação de práticas de gerenciamento da rotina. Para tanto, foi realizado um experimento com gestores e empregados da área de manutenção pesada de uma empresa de transporte aéreo. Nesta pesquisa foram aplicados questionários (apoiados nas proposições conceituais do gerenciamento da rotina) para captar as percepções de gestores e empregados que atuam em diferentes áreas de manutenção pesada de uma empresa de transporte aéreo de passageiros e cargas. Verificou-se que os respondentes percebem melhorias em processos operacionais e gerenciais e no desenvolvimento e gestão do conhecimento. Verificou-se também que os respondentes percebem impactos positivos da implantação e prática do gerenciamento da rotina, mas que essa percepção é menos favorável na função operação.
\end{abstract}

Palavras-chave: gerenciamento da rotina, gerenciamento de operações, qualidade.

\section{Introdução}

Em um ambiente dinâmico e de extrema competição seletiva no qual as organizações estão inseridas, as mesmas devem estar aptas a enfrentar as diversas transformações que ocorrem. Neste contexto, a competitividade organizacional é fator primordial para a sobrevivência no mercado atual. Analisando a organização em suas ações internas, Boljwin e Kumpe (1990) destacam que o 
poder de competição de uma organização é sustentado pelo trinômio: produtividade, qualidade e flexibilidade.

Conforme reportado em Goldman (2005) a aplicação dos conceitos de qualidade em negócios de empresas na América teve início com o retorno de W. Edwards Deming e Joseph Juran, do Japão nos anos 50 do século XX. Ambos haviam trabalhado na reconstrução da indústria japonesa onde puderam experimentar e aperfeiçoar ferramentas de melhoria da qualidade. Para Juran (1986) um sistema da qualidade total (Total Quality Management, TQM) é fundamentado em uma estrutura universal de pensamento da qualidade baseada no trinômio: qualidade orientada para processo; qualidade voltada para o cliente; e melhoria contínua da qualidade, sendo esta última baseada no gerenciamento da rotina. Várias pesquisas foram desenvolvidas relacionando o desempenho organizacional à implantação de TQM. Dentre os textos que reportam pesquisas desta natureza, citam-se aqui: Shetty (1993), Lemak et al. (1997), Easton e Jarrell (1998), Samson e Terziovski (1999), Reed et al. (2000), Nilsson et al. (2001), Kaynak (2003); e, Chonga e Rundus (2004). Neste contexto, vale registrar também o trabalho de Carpinetti e Martins (2001), que enfocou critérios de competitividade em empresas de diferentes setores da indústria brasileira, estabelecendo um mapeamento dos critérios de competitividade para estas empresas e desrtacando a importância dos critérios associados à qualidade.

Juran (1984) destaca que o gerenciamento da rotina é uma forma de induzir a melhoria contínua da qualidade, associando-o ao ciclo PDCA de Shewhart. O Ciclo PDCA (Shewhart (1928) e Shewhart (1938)) é proposto em um contexto de melhoria contínua baseado no Controle Estatístico do Processo. Ações de gerenciamento da rotina também são recomendadas em autores como Feigenbaum (1990), Ishikawa (1984), Deming (1982) e Harrington (1991).

Observa-se assim, que autores importantes indicam que a aplicação de técnicas de gerenciamento da rotina como método para a melhoria contínua pode possibilitar às organizações ajustar seus processos internos, amplificando o seu poder de competição.

\subsection{Questão da pesquisa}

Com base na revisão bibliográfica (ver seção 2 deste trabalho), foi possível detectar a existência da seguinte questão: "Qual a percepção dos membros da organização quanto a contribuição do gerenciamento da rotina para a melhoria contínua"? 


\subsection{Objetivo}

Objetivando contribuir à resposta para esta questão, desenvolveu-se uma pesquisa em uma empresa de transporte aéreo de passageiros que implementou em sua unidade de manutenção o gerenciamento da rotina na busca da melhoria contínua desta unidade.

\section{Revisão bibliográfica}

Foram realizadas pesquisas às bases de dados: Emerald, Gale e Proquest (Portal de Periódicos Capes); Scielo; Banco de teses e Dissertações da CAPES, à coleções de periódicos nacionais (Revista de Administração de Empresas, Revista de Administração Contemporânea, Gestão e Produção, Produção e Pesquisa Operacional - números anteriores À fase Scielo destas publicações). Essa pesquisa retornou referencial bibliográfico que permite estabelecer uma idéia do estado da arte no âmbito de gerenciamento de rotinas e do TQM, focando os resultados causados pela implementação deste tipo de gestão nos sistemas de produção. Um resumo do que se pode depreender deste referencial é reportado a seguir:

Scheibler (2003) investigou a aplicação conjunta do Balanced Scorecard (no nível estratégico) e do gerenciamento da rotina (no nível operacional) na construção de indicadores de desempenho organizacional. Segundo este autor, é necessário apoiar o Balanced Scorecard em indicadores operacionais para que se possa realimentar o nível estratégico. As conclusões do trabalho indicam a viabilidade da integração do BSC ao gerenciamento da rotina, obtendo-se um sistema de indicadores de desempenho que considera de forma integrada os níveis estratégico e operacional da organização.

Perez (1996) estudou a aplicação do gerenciamento de rotinas em empresas do setor de serviços. Em seu trabalho, Perez destaca que a principal característica necessária em uma organização prestadora de serviços para a aplicação dos princípios do gerenciamento da rotina é “que a organização em questão forneça serviços sob uma variação previamente conhecida desses serviços, o que significa dizer que os processos que compõem as ações para realização dos serviços se repetem intermitentemente"(PEREZ, 1996). Ou seja, a diversidade de produtos desta organização seja pequena. Ainda neste trabalho, conclui-se que a implantação de um sistema de gerenciamento de rotinas é um processo que "requer muito esforço daqueles que o implementam, e vale dizer que a ansiedade por resultados imediatos traz frustrações que em nada contribuem para a implantação" (PEREZ, 1996).

Apesar do rigor científico do trabalho realizado por Perez (que representa uma contribuição significativa à compreensão do processo de gerenciamento da rotina), esta conclusão é feita sem 
que o seu texto reporte um processo de medida e avaliação de "frustrações". Este fato corrobora para a necessidade de se elaborar um estudo para se captar as percepções quanto aos resultados da aplicação de técnicas de gerenciamento da rotina.

Reginato et al. (1996) analisa os princípios do gerenciamento da rotina na melhoria de processos em uma empresa de serviço de revelação fotográfica localizada na cidade de Santa Maria, RS, Brasil. A justificativa por se escolher este tipo de negócio é fundamentada mo fato de que neste negócio afirma-se ao cliente que se faz "revelação em uma hora". Este estudo (uma extensão do trabalho de Reginato (1996) aplicou o Diagrama de Causa-Efeito (também conhecido por Diagrama de Ishikawa) para se eliminar as principais causas de insatisfação dos consumidores do serviço.

Almeida (1998) investiga a aplicação dos conceitos de gerenciamento da rotina em uma empresa do setor florestal. Este trabalho busca a obtenção de "índices superiores de qualidade identificados pelos clientes". Ao final deste trabalho, baseado na análise de aspectos motivacionais e participativos, o autor conclui que o gerenciamento da rotina "é perfeitamente adequado ao ambiente de grandes empresas do setor florestal ... na busca de melhores padrões de qualidade.” . Deve-se registrar que esta é uma importante conclusão a que o autor chega baseado na sua análise dos aspectos motivacionais e organizacionais. No entanto, prevalece a dúvida: o "dono do negócio" percebe esta adequação perfeita?

Pedrozo (2001) estuda a aplicação do gerenciamento de rotinas na administração pública mais especificamente, na Secretaria das Finanças da Prefeitura Municipal de Santa Maria. Com base em pesquisas feitas juntos aos funcionários desta secretaria, foram padronizadas atividades de rotina e solucionados problemas vinculados a estas atividades.

Choi e Eboch (1998) avaliam as correlações entre TQM e seu impacto na satisfação dos clientes e no desempenho da planta. Este trabalho identifica fortes correlações entre a implantação do TQM e a satisfação dos clientes, assim como entre a implantação do TQM e o desempenho da planta. No entanto não são identificadas fortes correlações entre desempenho da planta e satisfação dos clientes. Os autores explicam este fato paradoxal considerando que em algumas situações a implantação do TQM está associada à melhoria do desempenho da planta e em outras situações à satisfação do cliente. Esta pesquisa utilizou-se de uma abordagem do tipo survey que considerou 330 empresas de manufatura situadas nos Estados Unidos.

Mesquita e Alliprandini (2003) investigam o conjunto de competências que uma organização deve possuir para obter sucesso na implantação de sistemas de certificação ISO. O estudo de caso efetuado contempla três empresas do setor automotivo, todas já certificadas pelas normas ISO.

Bianco e Salerno (2001) analisam os impactos da implantação de programas de TQM em empresas brasileiras. Foi realizado um estudo de campo considerando empresas de manufatura 
localizadas no Estado de São Paulo e líderes em seus respectivos mercados. Foram consideradas 11 empresas de grande porte, mais de quinhentos empregados, que estavam inseridas em programas de TQM há pelo menos dois anos. Os resultados desta pesquisa indicaram que o modelo de disseminação ocorre em um contexto top down, com alterações nas relações com os fornecedores, mas com a lógica organizacional afastando-se pouco do modelo taylorista.

Também buscando identificar os impactos oriundos da implantação de TQM no desempenho organizacional, Samson e Terziovski (1999) analisam o desempenho de 1200 empresas de manufatura localizadas na Oceania (Austrália e Nova Zelândia). Este trabalho identificou um relacionamento significante entre TQM e desempenho organizacional, tendo sido explicadas mudanças de desempenho pelo emprego do TQM. No entanto, nem todas as práticas de TQM apresentaram uma forte relação com os resultados do desempenho organizacional. Particularmente as variáveis associadas a ferramentas de melhoria contínua apresentaram um menor impacto no desempenho organizacional do que as variáveis relacionadas a fatores comportamentais, como liderança e gerenciamento de recursos humanos.

Salada (2002) apresenta uma aplicação do gerenciamento de rotinas através de um modelo de estabilização de processos. Este modelo é fundamentado em: padronização do processo; treinamento operacional; tratamento de falhas; e, a auditoria de padrões. Um ponto de destaque deste trabalho é a aplicação do controle estatístico no gerenciamento da rotina. Este trabalho reporta uma aplicação deste modelo a uma empresa da indústria metalúrgica do Rio Grande do Sul - mais especificamente no processo de fabricação de arame farpado produzido por esta empresa. Segundo os autores a aplicação deste modelo permitiu mapear, avaliar, revisar e aperfeiçoar a fabricação de arame farpado pela empresa.

Barbalho (2001) identificou e descreveu a percepção de gestores e funcionários de agências bancárias de instituição financeira sobre as práticas de gestão adotadas nessas agências, tendo como referência os Critérios de Excelência do Prêmio Nacional da Qualidade. O estudo verificou que os respondentes percebiam envolvimento dos administradores das agências na disseminação dos objetivos estratégicos e institucionais, bem como boas práticas de gestão; também indicou a existência de pouco envolvimento dos mesmos no processo de formulação das estratégias e planos de trabalho.

Em pesquisa junto a empresas da Malásia, Thiagarajan e Zairi (1998), a partir de uma ferramenta para auto-avaliação, corroboraram com a afirmação de que a percepção do comprometimento e envolvimento dos gestores é principal fator crítico de sucesso na implantação do TQM.

Dooley (1998) pesquisaram a percepção das lacunas entre os resultados esperados e os resultados obtidos na implantação do TQM. Os autores concluíram que o sucesso é função dos 
resultados percebidos comparados aos esperados, e não somente dos resultados efetivamente obtidos.

Caruana e Pitt (1997), por sua vez, identificaram que a motivação para a busca da melhoria da qualidade do serviço é a percepção de que esta aumenta a satisfação do cliente e, portanto, afeta positivamente o desempenho da organização - este fato destaca a importância de se captar as percepções internas quanto aos impactos oriundos da implantação de ações de melhoria.

Lipe e Saterio (2000) apud Waal (2003) identificaram que limitações cognitivas dos gestores podem levar a utilizações diferentes de um mesmo sistema de medição e controle de desempenho, fazendo com que a organização não se beneficie plenamente de sua utilização.

Com base nos trabalhos citados, verifica-se que a percepção dos funcionários e clientes de uma empresa à respeito da influência TQM no desempenho organizacional exerce um papel importante no sucesso da organização. Observou-se também uma lacuna ou carência de trabalhos científicos que busquem captar esta percepção.

\section{Descrição da pesquisa}

Para que fosse possível mapear os impactos percebidos pela organização os benefícios percebidos pela organização e sua respectiva relevância para a obtenção de resultados, a pesquisa foi estruturada em dois contextos:

- Pesquisa da percepção relativa ao impacto do gerenciamento da rotina em melhorias operacionais e gerenciais, e ao desenvolvimento e gestão do conhecimento; e,

- Pesquisa 2 da percepção relativa aos aspectos considerados mais relevantes para o alcance de resultados.

A seguir descrevem-se as etapas de aplicação destas pesquisas e, também os resultados obtidos pela realização destas.

\subsection{Objeto de estudo}

O objeto de estudo desta pesquisa foi a área de manutenção pesada de uma empresa brasileira de transporte aéreo de passageiros. Essa área era responsável pelo planejamento, execução e teste de manutenção preventiva de sua frota de aeronaves. A área era constituída por uma gerência industrial, a qual reportava-se à diretoria de produção. Respondendo à gerência industrial 
encontravam-se: Hangares A e B; Oficinas; Planejamento e Controle da Produção; e, Suporte Técnico.

É importante lembrar que, à época do início da implantação do gerenciamento da rotina, a empresa colocou como metas a redução de: 10\% do tempo de manutenção; e, $15 \%$ do custo dos materiais aplicados às manutenções.

\subsection{Aspectos pesquisados e instrumento de coleta}

A pesquisa focou de aspectos referentes a melhorias: operacionais e gerenciais; e, a gestão do conhecimento. Para a coleta de dados foi construído um questionário (Anexo I). Os itens abordados na coleta de dados foram escolhidos com base na revisão bibliográfica, que destaca as vantagens da implantação de sistemas de gerenciamento da rotina. Estes itens estão apresentados a seguir:

- Melhoria/desenvolvimento dos processos operacionais: refere-se à melhoria/ desenvolvimento de práticas melhores de manutenção, incluindo organização do trabalho, divisão de tarefas, limpeza da área de trabalho, disponibilidade de ferramentas e equipamentos de trabalho e conformidade às normas/ padrões estabelecidos. Essas melhorias seriam decorrentes da análise dos processos e da execução de ações corretivas para as barreiras identificadas ao alcance das metas.

- Melhoria/ desenvolvimento dos processos gerenciais: refere-se à melhoria/ desenvolvimento de práticas melhores de acompanhamento do trabalho e seus resultados, da identificação de problemas. Segundo Campos (2002), o melhor gerenciamento é uma decorrência da implantação do gerenciamento da rotina, centrado em análises e ações buscando o alcance de metas definidas.

- Melhoria/ desenvolvimento de relações entre grupos e áreas: refere-se à melhor capacidade de entendimento e atendimento das necessidades e requisitos entre áreas entre as quais existe uma relação cliente interno-fornecedor interno. Ainda segundo Campos (2002), o gerenciamento da rotina preconiza a clara definição da autoridade e responsabilidade de cada pessoa, bem como o tratamento de problemas localizados ou inter-funcionais, o que possibilitaria a melhoria/ desenvolvimento das relações entre grupos e áreas.

- Melhoria/ desenvolvimento da liderança: refere-se à melhoria da capacidade de liderar pessoas para a obtenção dos resultados esperados. Essas melhorias seriam decorrentes da definição de objetivos claros e compartilhados, da disponibilidade de dados que possibilitassem a avaliação contínua dos processos e do desempenho das pessoas, orientando-as adequadamente na sua rotina, bem como do treinamento das pessoas para a execução de suas atividades. 
- Melhoria/desenvolvimento da motivação: refere-se à melhoria na vontade das pessoas na organização em perseguir os resultados almejados pela organização, sentindo-se bem consigo mesmas. Essas melhorias seriam decorrentes da participação dos empregados na identificação e solução dos problemas, da clareza em relação aos objetivos a serem perseguidos, bem como da melhoria do ambiente de trabalho.

- Melhoria da comunicação da gerência com os empregados: refere-se à melhoria da capacidade da gerência e dos empregados em compartilharem experiências e conhecimento de forma a obter os resultados desejados pela organização. A melhoria da comunicação da gerência com os empregados decorreria da necessidade das funções operacionais funcionarem bem para que as funções gerenciais possam ser adequadamente executadas.

- Clara identificação dos objetivos organizacionais: refere-se à melhor compreensão dos objetivos organizacionais, possibilitando que os mesmos sejam buscados de forma consistente por todos na organização. Essa melhoria seria decorrente da definição de metas claras e aos indicadores de desempenho associados a essas metas.

Além destes fatores, a literatura pesquisada afirma que o gerenciamento da rotina estimula a gestão do conhecimento. Assim, foram avaliadas percepções quanto aos seguintes aspectos:

- Domínio da lógica de custo e benefício: refere-se à capacidade de entendimento da formação dos custos e dos benefícios que estes proporcionam à operação e à gestão. Esse conhecimento deveria ser obtido uma vez que a meta referia-se à redução de custos de materiais aplicados.

- Adequação dos sistemas de informação às necessidades da operação: refere-se à capacidade dos sistemas de informação estarem melhor preparados para atender às necessidades do dia a dia da operação e da gerência. Novamente, dado que os processos dependiam de sistemas para funcionarem adequadamente, principalmente no que se refere ao planejamento e controle das operações, os sistemas deveriam ter evoluído para adequar-se aos mesmos, suportando melhor as necessidades da operação.

- Domínio da tecnologia necessária ao desenvolvimento dos processos operacionais: referese ao conhecimento necessário para identificar oportunidades, propor melhorias e inovações e operar adequadamente os processos de manutenção e de apoio à manutenção. Uma vez que foram realizadas diversas análises dos processos envolvidos e da organização do trabalho, bem como treinamento das pessoas nessas técnicas de análise, deveria ter ocorrido uma percepção de aumento de domínio da tecnologia necessária ao desenvolvimento dos processos operacionais.

- Desenvolvimento de competências novas: refere-se à capacidade de desenvolver e aplicar novos conhecimentos e habilidades organizacionais e disseminá-los entre os empregados. Novamente, as pessoas foram treinadas em técnicas de análise e de solução de problemas, sendo 
que nos processos, as tarefas críticas foram padronizadas para posterior treinamento dos operadores; dessa forma, deveria ter ocorrido uma percepção de desenvolvimento de novas competências.

- Capacidade de solução de problemas: refere-se à capacidade de desenvolver e aplicar soluções aos problemas (anomalias) encontrados na rotina do trabalho do dia a dia. A partir do treinamento em técnicas de solução de problemas, da definição, monitoramente e análise dos indicadores, deveria ocorrer uma percepção de que havia aumentado a capacidade de solução dos problemas encontrados no dia-a-dia.

- Equalização do conhecimento entre os funcionários: refere-se à capacidade de disseminar o conhecimento entre os empregados através de treinamento e educação, aplicando-o de maneira rotineira no seu dia a dia. Como vários operadores foram treinados nas tarefas consideradas críticas, esperava-se que os procedimentos estivessem acessíveis a todos e que houvesse a percepção de que os conhecimentos haviam sido eqüalizados entre os funcionários.

\subsection{Descrição da aplicação das pesquisas}

A pesquisa foi aplicada em reuniões com os respondentes, com apoio do questionário. Durante estas reuniões um facilitador (um dos autores deste artigo) apresentava o questionário aos respondentes e fica disponível para elucidar dúvidas quanto as questões presentes no instrumento de coleta.

A realização da pesquisa ocorreu dois anos após a implantação do sistema de gerenciamento da rotina à funcionários de diferentes áreas e diferentes níveis hierárquicos dentro da organização, que faziam parte da organização antes da implantação do gerenciamento da rotina e depois da implantação deste. Assim, a pesquisa foi aplicada a amostra reportada na Tabela1 - destacando-se que, no caso da pesquisa da percepção relativa aos aspectos considerados mais relevantes para o alcance de resultados, os respondentes foram os gerentes e supervisores/ coordenadores das áreas participantes:

Tabela 1: Amostra à qual foram aplicados os questionários de pesquisa

\begin{tabular}{|l|l|l|l|l|l|}
\hline \multicolumn{2}{|l|}{ Nível hierárquico } & \multicolumn{2}{l|}{} \\
\hline Área & Gerência & Supervisão/coordenação & Lideranças & Mecânicos & Total \\
\hline Industrial & 1 & & & & 1 \\
\hline Hangar & 1 & 2 & 24 & 19 & 46 \\
\hline Engenharia & & & & 3 & 3 \\
\hline PCP & 1 & 1 & & 8 & 10 \\
\hline Oficina & 1 & 4 & 9 & 14 & 28 \\
\hline Total & 4 & 7 & 33 & 44 & 88 \\
\hline
\end{tabular}

Autoria própria (2008) 
Sobre o nível de resposta da amostra registra-se que:

- Todos os membros da amostra responderam à pesquisa;

- 100\% dos gerentes (ou pessoas em postos de gerência), supervisores/ coordenadores e líderes que haviam participado do programa desde seu início e ainda se encontravam na organização;

- 100\% das pessoas alocadas à área de Suporte Técnico/Engenharia e ao Planejamento e Controle da Produção (PCP);

- 10\% dos mecânicos alocados aos Hangares e Oficinas, escolhidos aleatoriamente a partir do quadro de funcionários existente no início do programa de implantação do gerenciamento da rotina e ainda pertencente à organização.

\section{Resultados da pesquisa}

Os resultados da pesquisa são apresentados a seguir considerando-se os dois aspectos centrais da mesma:

- Pesquisa de percepção relativa ao impacto do gerenciamento da rotina em melhorias operacionais e gerenciais e ao desenvolvimento e gestão do conhecimento;

- Pesquisa de percepção relativa aos aspectos considerados mais relevantes para o alcance de resultados.

\subsection{Percepções relativas ao impacto do gerenciamento da rotina}

O gráfico 1 ilustra apresentar a distribuição das respostas apresentadas pelos membros da função gerência que fizeram parte da pesquisa. Ao se analisar este gráfico observa-se que:

- Nenhum dos gerentes discordou plenamente dos resultados alcançados pelo gerenciamento da rotina para os diversos itens analisados.

- Pelo menos 75\% dos gerentes concordaram plenamente ou concordaram que o gerenciamento da rotina trouxe resultados positivos relacionados aos itens: melhorias em processos operacionais e gerenciais, melhorias nas relações entre áreas, motivação dos empregados, adequação dos sistemas de informação, clareza dos objetivos organizacionais, domínio da tecnologia necessária ao desenvolvimento dos processos operacionais, desenvolvimento de novas 
competências, capacidade de solução de problemas e equalização do conhecimento entre os empregados.

- Pelo menos $25 \%$ dos gerentes discordam ou discordaram plenamente que o gerenciamento da rotina tenha possibilitado uma melhor compreensão da lógica de custo-benefício inerente ao negócio (25\%) mesmo sendo uma das metas relacionada a custos. bem como ao desenvolvimento/ melhoria das lideranças, tanto própria quanto dos níveis hierárquicos sob sua responsabilidade $(50 \%)$.

Gráfico 1: Respostas da função Gerência: Número de respondentes: quatro gerentes

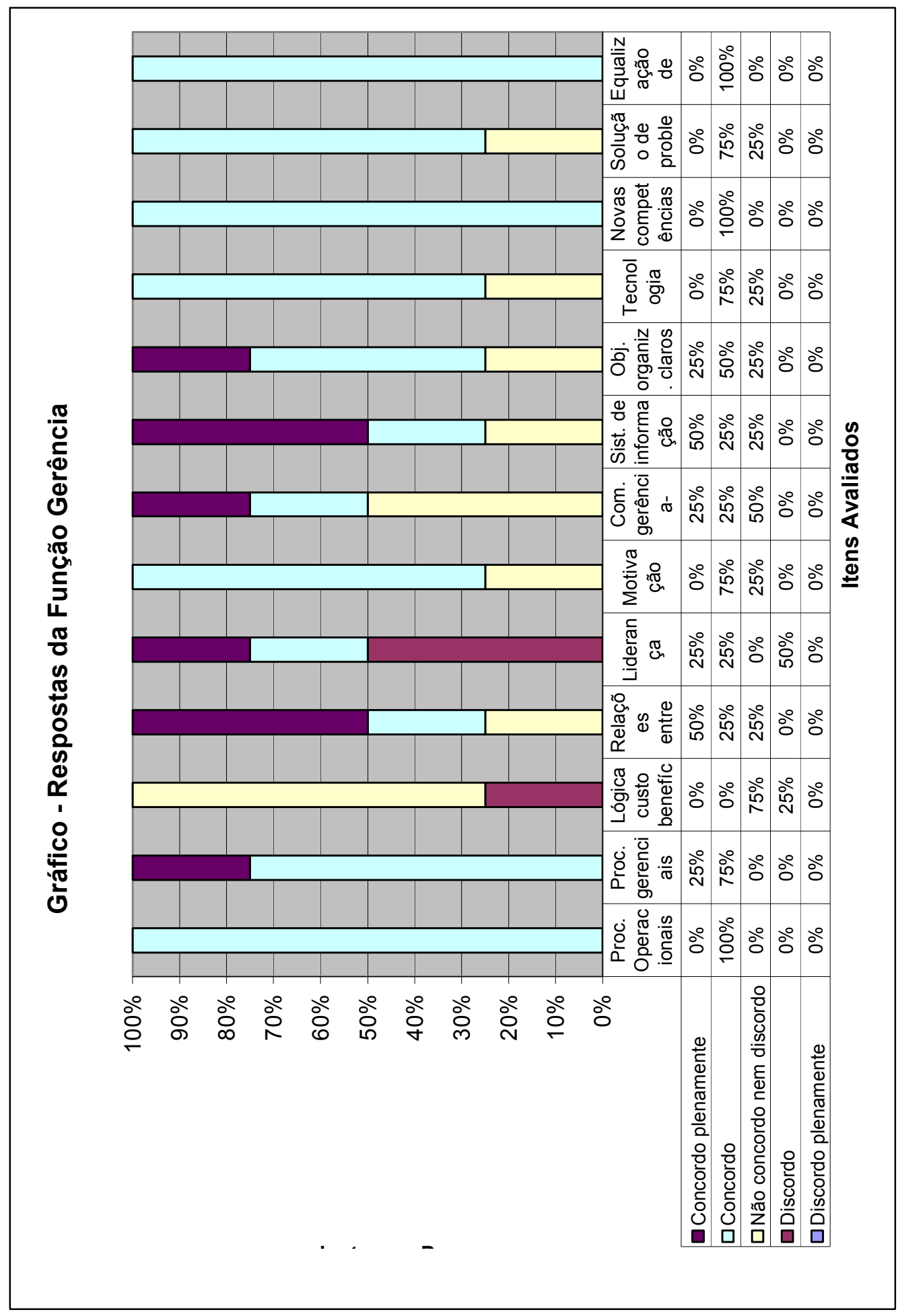


- Pelo menos 25\% dos gerentes não concordam nem discordam que o gerenciamento da rotina tenha proporcionado: melhor compreensão da lógica de custo-benefício inerente ao negócio (reforçando o posicionamento verificado acima), melhoria/ desenvolvimento das relações entre áreas (25\%), motivação dos empregados (25\%), comunicação gerência-empregado (50\%), adequação dos sistemas de informação (25\%), clareza dos objetivos organizacionais (25\%), domínio da tecnologia necessária ao desenvolvimento dos processos $(25 \%)$ e capacidade de solução de problemas $(25 \%)$.

O gráfico 2 apresenta a distribuição das respostas apresentadas pelos membros da função gerência que fizeram parte da pesquisa. Analisando este gráfico é possível concluir que:

- Nenhum dos supervisores/ coordenadores discordou plenamente dos resultados alcançados pelo gerenciamento da rotina para os itens avaliados.

- Pelo menos 75\% dos supervisores/ coordenadores concordaram plenamente ou concordaram que o gerenciamento da rotina trouxe resultados positivos relacionados aos itens: melhorias em processos operacionais, compreensão da lógica de custo-benefício, desenvolvimento das lideranças, clareza de objetivos organizacionais, domínio da tecnologia necessária ao desenvolvimento dos processos operacionais, desenvolvimento de novas competências e capacidade de solução de problemas.

- No quesito liderança, verifica-se um posicionamento dos supervisores/coordenadores bastante diferente daquele obtido pelos gerentes: $100 \%$ dos supervisores/coordenadores concordaram ou concordaram plenamente que houve desenvolvimento das lideranças, enquanto $50 \%$ dos gerentes responderam que não concordavam com as melhorias neste item. Esse posicionamento pode decorrer de uma percepção diferenciada entre gerentes e supervisores/ coordenadores sobre o que é liderança, ou como esta se manifesta.

- Vale a pena ressaltar que, apesar das respostas dos supervisores concordando com a afirmação de que tenha ocorrido desenvolvimento das lideranças, o maior índice de discordância foi relativo ao item melhoria dos processos gerenciais (29\%), sendo essa percepção possivelmente decorrente de um conceito de que a liderança manifesta-se de forma individual e personificada, e não através de processos que a viabilizam no dia-a-dia (como ocorre, por exemplo, com a gestão de resultados e treinamento).

- Pelo menos $25 \%$ dos supervisores/coordenadores não concordaram nem discordaram com a afirmação de que o gerenciamento da rotina tenha proporcionado: melhoria/ desenvolvimento das relações entre áreas, motivação dos empregados, melhoria da comunicação gerência-empregado, 
adequação dos sistemas de informação e, principalmente, equalização do conhecimento entre os empregados (43\%). Neste item, observa-se que a disseminação do conhecimento entre os empregados deveria ocorrer através do treinamento no trabalho (OJT - on job training), a qual seria uma das responsabilidades dos gestores na função de liderança. Logo, apesar dos supervisores/ coordenadores perceberem uma melhoria/desenvolvimento da característica de liderança entre os gestores, a mesma não teria sido suficiente para disseminar o conhecimento entre os empregados.

Gráfico 2: Respostas da função Supervisão (Número de respondentes: sete supervisores/ coordenadores)

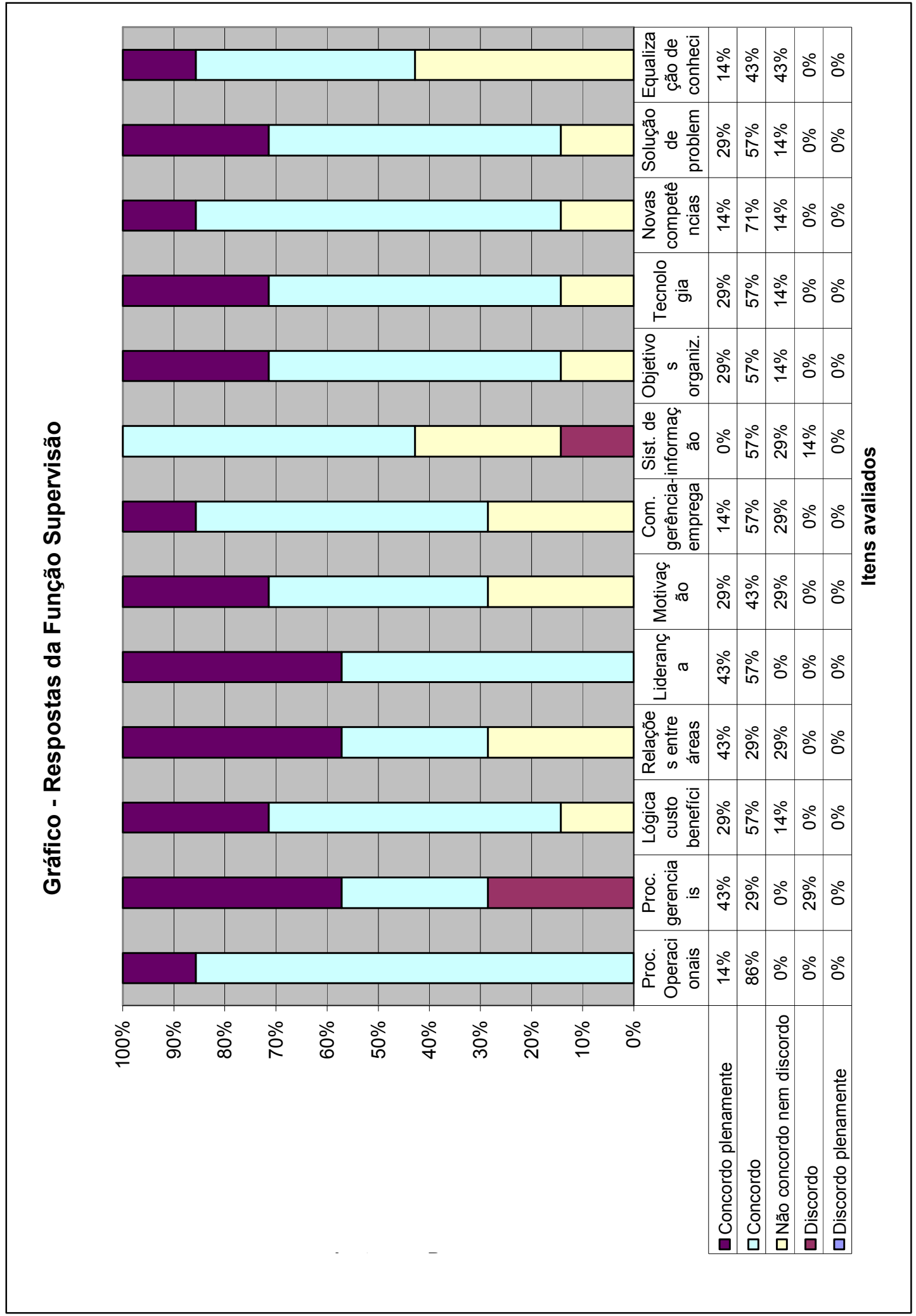


Também vale observar que a melhoria do relacionamento entre áreas era considerada uma responsabilidade dos gestores na função de supervisão/ coordenação, sendo que estes não perceberam que o gerenciamento da rotina tenha proporcionado melhorias em relação a este item.

O gráfico 3 apresenta a distribuição das respostas apresentadas pelos membros da função liderança que fizeram parte da pesquisa. A função liderança é aquela que possui contato direto com o empregado no caso de hangares e oficinas, não existindo nas áreas de PCP e Suporte Técnico/ Engenharia. Logo, espera-se que esta retrate as dificuldades sentidas na supervisão de pessoas, e o quanto o gerenciamento da rotina ajudou-os ou não a eliminar os problemas surgidos no dia-a-dia. Ao se analisar este gráfico é possível observar que, no caso da liderança:

- Não houve nenhum item que tenha tido $100 \%$ de concordância. No entanto, verificou-se que pelo menos $75 \%$ dos líderes consultados concordaram ou concordaram plenamente que houve resultados positivos, advindos da implantação do gerenciamento da rotina, para os seguintes itens avaliados: melhoria/ desenvolvimento dos processos operacionais, melhoria/ desenvolvimento dos processos gerenciais, melhoria/ desenvolvimento da liderança, domínio da tecnologia necessária ao desenvolvimento dos processos operacionais, e capacidade de solução de problemas.

- 33\% dos respondentes desse mesmo grupo discordou ou discordou totalmente da afirmação de que tenham ocorrido melhorias nos sistemas de informação.

- Pelo menos $25 \%$ dos respondentes em função de liderança não concordaram nem discordaram sobre os itens avaliados referentes à melhoria da comunicação gerência-empregado (33\%), lógica de custo-benefício (30\%), objetivos organizacionais claros (27\%).

- Para a função liderança o gerenciamento da rotina não foi percebido como um impulsionador da clareza dos objetivos organizacionais, mesmo havendo metas específicas a serem atingidas. Não parece ter havido uma clara comunicação que as metas eram o objetivo organizacional a ser perseguido, ou mesmo pode ter ocorrido no dia-a-dia um eventual desvio para outras metas que não fossem aquelas institucionalizadas através do gerenciamento da rotina.

- Os respondentes também não perceberam uma melhor compreensão da lógica de custobenefício como decorrente do gerenciamento da rotina. Ou seja, as análises efetuadas e os dados disponibilizados não possibilitaram, para 30\% dos líderes, que esse item apresentasse melhorias.

Comparativamente aos supervisores/coordenadores, os líderes também concordaram ou concordaram plenamente que houve desenvolvimento da liderança. 
Gráfico 3: Respostas da função Liderança (Número de respondentes: 33 líderes)

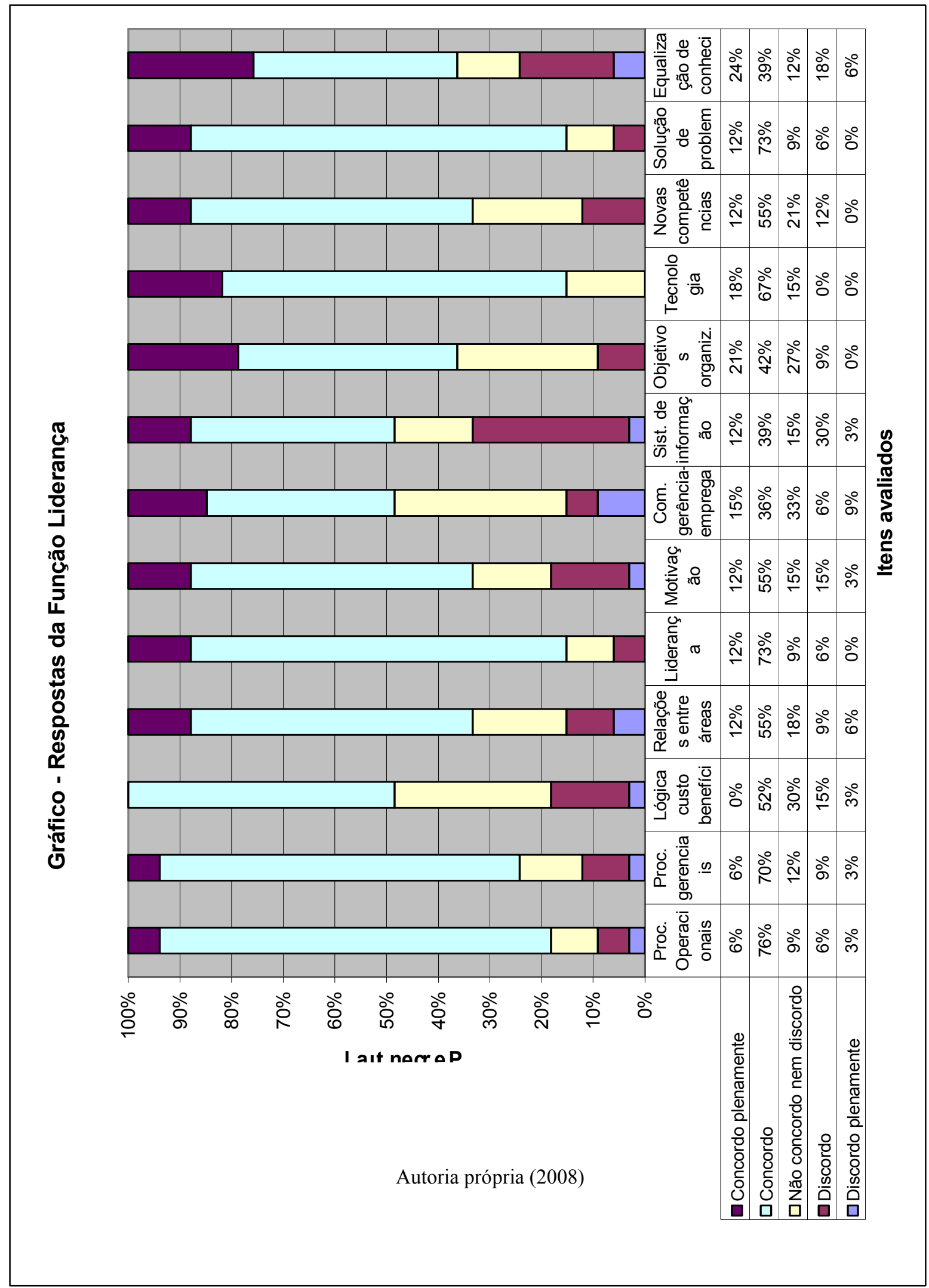

O gráfico 4 apresenta a distribuição das respostas apresentadas pelos membros da função operação que fizeram parte da pesquisa. 
Gráfico 4: Respostas da função Operação (Número de respondentes: 44 empregados)

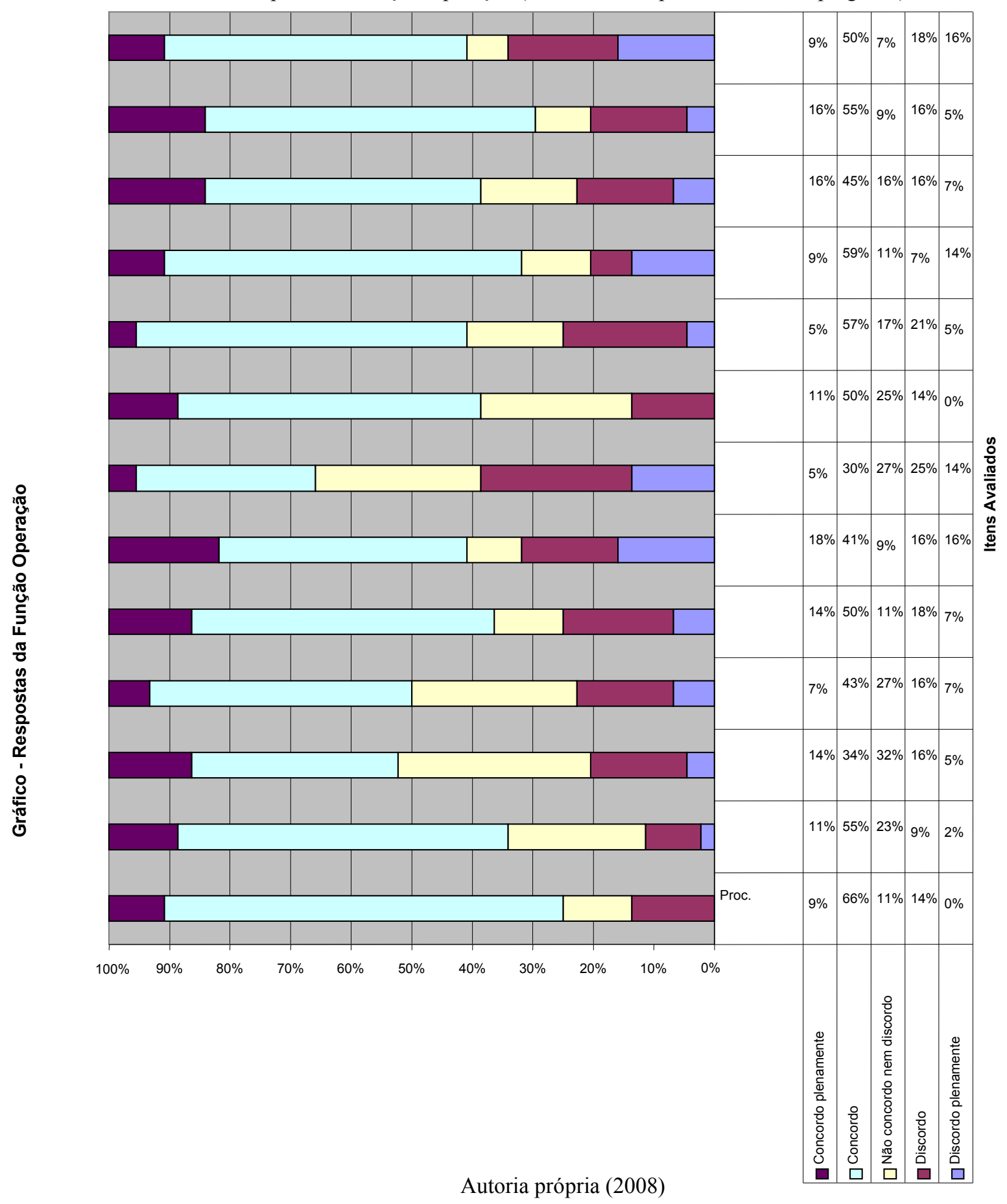

A função operação é aquela responsável por desenvolver as atividades do dia-a-dia, seguindo procedimentos previamente estabelecidos. A pesquisa com o s membros desta função permite mapear os efeitos percebidos como oriundos da implantação do gerenciamento da rotina $€$, no dia-a-dia das atividades de rotina. Ao analisar o gráfico 4, é possível concluir que:

- Os maiores índices de concordância (respostas "concordo plenamente" mais "concordo") ocorreram para os itens melhoria dos processos operacionais ( $75 \%$ de concordância) e melhoria da capacidade de solução de problemas (70\%). 
- Os itens que obtiveram o maior número de respostas "discordo" e "discordo plenamente" foram: melhoria da comunicação gerência-empregado (39\%), equalização do conhecimento (34\%) e motivação (32\%). Ou seja, os empregados em função de operação esperavam possivelmente que o gerenciamento da rotina permitisse canais mais abertos de comunicação, uma maior disseminação dos conhecimentos (sendo que muitos se restringem em função do grau de senioridade dos mecânicos) e motivação.

\section{2. . Percepções relativas a relevância dos aspectos pesquisados para o alcance de resultados}

Aos gerentes e supervisores/coordenadores foi solicitado que pontuassem os aspectos avaliados através do preenchimento do questionário específico, de forma que pudesse ser definida uma escala de importância entre eles. Essa priorização permitiu que fosse analisado se os itens considerados mais relevantes para o alcance de resultados eram percebidos como tendo efetivamente contribuído para os mesmos. A pontuação obtida em relação à máxima pontuação possível é ilustrada no gráfico 5.

A análise do gráfico 5, permite verificar que os itens considerados mais relevantes para o alcance de resultados foram "objetivos organizacionais claros" (ou "clareza dos objetivos organizacionais"), "processos operacionais" (ou "melhoria/desenvolvimento dos processos organizacionais") e "relações entre áreas" (ou "melhoria/desenvolvimento das relações entre grupos e áreas"). Esses três itens obtiveram acima de 50\% do total de pontos máximo que poderiam ser atingido.

Foi ainda verificado que não há coincidência entre os itens que foram classificados como mais relevantes para o alcance de resultados e aqueles que obtiveram percepções mais favoráveis em relação ao seu impacto em melhorias operacionais e gerenciais e ao desenvolvimento e gestão do conhecimento.

Embora não seja ilustrado neste gráfico, verificou-se uma não convergência entre as percepções sobre o grau de relevância entre os gerentes e supervisores em relação, o que pode ter gerado conflito durante a implantação do gerenciamento da rotina.

Para que houvesse ocorrido um maior alinhamento de percepções entre os responsáveis pela implantação do gerenciamento da rotina, seria importante a discussão - prévia à implantação - de quais seriam os fatores críticos de sucesso da mesma, e como garanti-los ao longo dos trabalhos. 


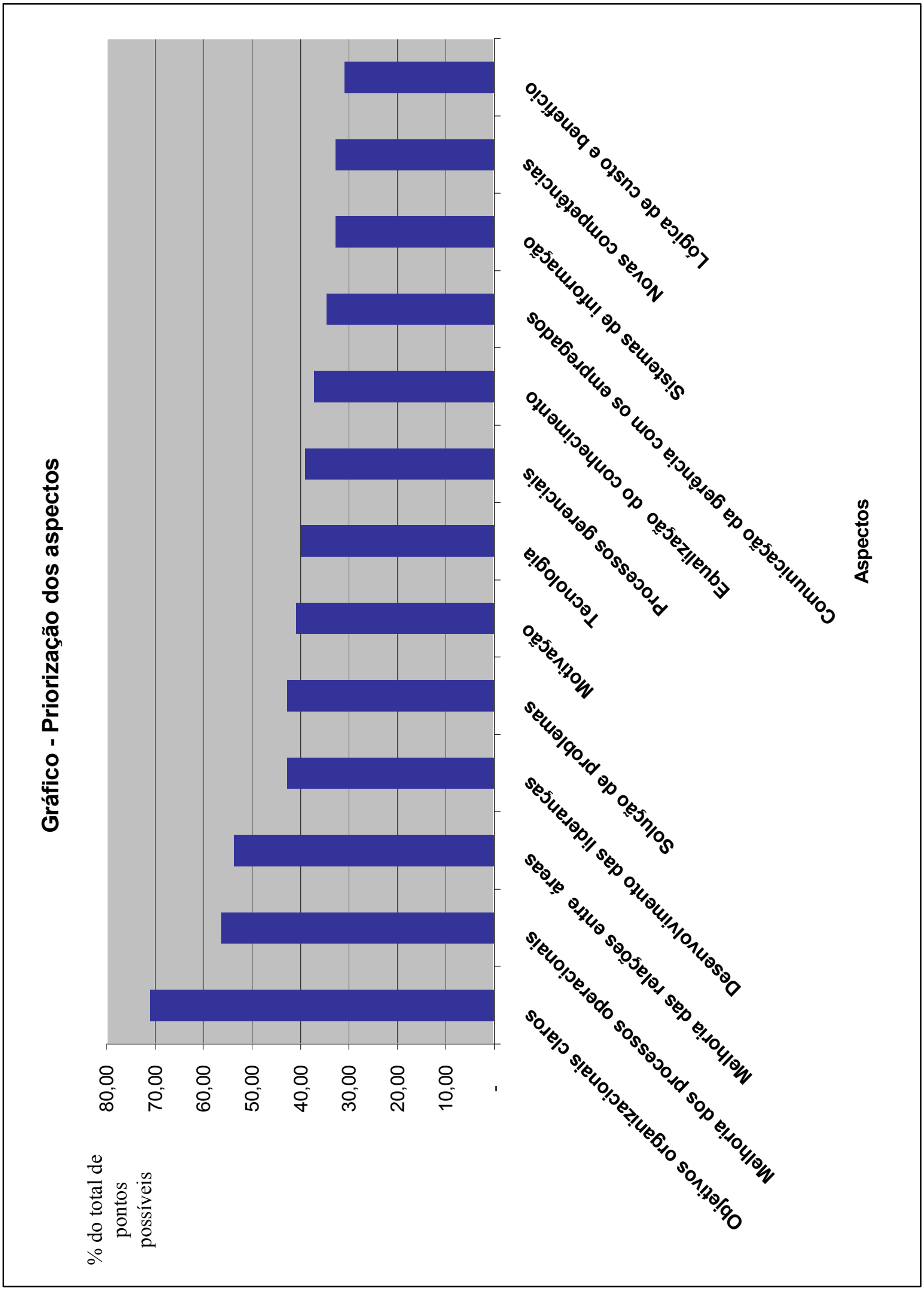

Autoria própria (2008) 


\section{Conclusões}

Durante a pesquisa bibliográfica foram verificados na literatura indícios de que a implantação e prática do gerenciamento da rotina possibilitariam o alcance de metas através de ou concomitante a melhorias operacionais e gerenciais, bem como ao desenvolvimento e gestão do conhecimento.

No entanto, a mesma pesquisa bibliográfica não identificou trabalhos que investiguem a percepção da validade destas afirmações em casos práticos. Assume-se, dessa forma, que o alcance das metas é obtido, sem, no entanto verificar as percepções quanto a intensidade destas melhorias.

No presente trabalho foi feita uma proposta de modelagem para se mapear as diferentes percepções intra-organizacionais quanto aos impactos da adoção de um sistema baseado em gerenciamento da rotina. A modelagem proposta foi aplicada a um caso específico, desenvolvido para experimentar a aplicação da mesma. Os resultados deste caso permitem concluir que as principais lacunas ocorreram nos seguintes contextos:

- A percepção dos diferentes níveis organizacionais não é homogênea: há uma percepção mais positiva sobre os efeitos da implantação e prática do gerenciamento da rotina pelos níveis hierárquicos superiores - no caso, para os respondentes das funções gerência e supervisão/ coordenação;

- As áreas de apoio e operacional não apresentaram, de forma consolidada, diferenças significativas de percepção. Diferenças de percepção identificadas quando analisados individualmente os itens não foram consideradas críticas, visto que não houve antagonismo nas respostas.

- Considerando a média das respostas, houve uma percepção de que, de fato, o gerenciamento da rotina originou uma melhoria nos itens avaliados.

Além dessas lacunas foi possível identificar os maiores e os menores impactos positivos percebidos para os diferentes níveis funcionais, conforme destacado a seguir:

\section{- Para a função operacional:}

- Aspecto com maior impacto positivo: processos operacionais.

- Aspectos com menores impactos positivos: comunicação entre gerência e força de trabalho.

- Para a função liderança:

- Aspectos com maiores impactos positivos: solução de problemas, tecnológica; liderança; e, processos operacionais. 
- Aspectos com maiores impactos positivos foram: comunicação com a gerência; e, sistema de informação.

\section{- Para a função supervisão:}

- Aspectos com maiores impactos positivos foram: equalização de conhecimento; e, sistema de informação.

- Aspectos com menores impactos positivos: liderança; e, processos operacionais.

- Para a função gerência:

- Aspectos com maiores impactos positivos foram: equalização de conhecimento; novas competências; processos organizacionais; e, processos operacionais

- Aspectos com menores impactos positivos: liderança; e, comunicação com a gerência.

Os aspectos considerados mais importantes pela alta gerência foram: clareza dos objetivos organizacionais; melhoria de processos; e, melhoria da comunicação intra-organizacional. Observa-se que estes aspectos coincidem com aqueles citados por pelo menos umas das funções, como os de menor impacto positivo percebido.

A realização do experimento de aplicação do caso permitiu observar que a utilização da abordagem proposta para o mapeamento de percepções é factível. No entanto, assim como na maioria das situações de modelagem de problemas de gestão, os resultados obtidos são particulares ao experimento. Ou seja: não podem ser diretamente extrapolados para situações diversas da investigada no caso e o uso dos resultados por analogia deve ser feito de forma cuidadosa e metódica.

\section{Sugestões para futuros desenvolvimentos}

A aplicação do questionário de percepção relativa aos aspectos considerados mais relevantes para o alcance de resultados para o nível operacional da organização, permitindo ampliar a análise das percepções das diferentes funções organizacionais;

A aplicação da abordagem proposta em outros casos, objetivando a construção de um referencial mais amplo e de uma amostra que permita o uso de técnicas estatísticas para a análise do grau de correlação entre os aspectos investigados. 


\begin{abstract}
Several bibliographical references tell us that the use of routine management procedures in organizations generates continuous improvement and performance gains into that one. In despite of this "true" it isn't found in specialized literature any research that verifies the perception of the gains that results form the use of routine management in organizations. Present work aims to get the perceptions of management team and workforce about the impact of routine management adoption over organizational performance. To do this, questionnaires (supported by conceptual propositions of the routine management) were applied to management and workflow of the maintenance section of an aircraft transport company that have adopted routine management. More specifically, the research was applied in the organizational unit responsible for the aircrafts heavy maintenance, involving all the functions - managing, supervising, leadership and operations, summing up 88 employees. The respondents perceived improvements that came from routine management implementation. These improvements were perceived either on operational and management process as in knowledge management. The differences between the perceptions on different organizational level are highlighted too. So it was also verified that although the respondents notice positive impacts in the implementation and practice of the routine management, this perception is less favorable in the operational function.
\end{abstract}

Key-words: Routine Management, Operations Management, Perception, Index, Performance, Quality.

\title{
REFERÊNCIAS
}

\section{ALMEIDA, A. R .C. D. Gerenciamento da Rotina Visando a Melhoria da Qualidade na Empresa Florestal.}

Dissertação (Mestrado em Engenharia Mecânica: Qualidade), Departamento de Engenharia Mecânica, UNICAMP, Campinas, 1998.

BARBALHO, J.P. Gestão pela excelência em agências bancárias: um estudo de caso no Banco do Brasil. Dissertação (Mestrado em Engenharia da Produção), Programa de Pós-Graduação em Engenharia da Produção, Universidade Federal de Santa Catarina, Florianópolis, 2001. 130 p.

BIANCO, M.D. F. e SALERMO, M. S. Como o TQM opera e o que muda nas empresas? Um estudo a partir de empresas líderes no Brasil. Gestão e Produção, v.8, n.1, p.56-67. 2001.

cross ${ }^{\text {ref }}$

BOLJWIN, P. T. e KUMPE, T. Manufacturing in the 1990's - Productivity, Flexibility and Innovation. Long Range Planning, v.23, n.4, p.44-57. 1990.

cross ref

CAMPOS, V.F. Gerenciamento da rotina do dia-a-dia. Belo Horizonte: Editora de Desenvolvimento Gerencial, 2002.

CARPINETTI, L. C. R. e MARTINS, R. A. Continuous improvement strategies and production competitive criteria: some findings in Brazilian industries. Total Quality Management, v.12, n.3, p.281-291. 2001.

cross ${ }^{\text {ref }}$

CARUANA, A. e PITT, L. INTQUAL - an internal measure of service quality and the link between service quality and business performance European Journal of Marketing, v.31, n.7. 1997.

CHOI, T.Y. e EBOCH, K. The TQM Paradox: Relations among TQM practices, plant performance, and customer satisfaction. Journal of Operations Management, v.17, p.59-75. 1998.

cross ${ }^{\text {ref }}$

CHONGA, V. K. e RUNDUS, M. J. Total quality management, market competition and organizational performance. The British Accounting Review v.36 p.155-172. 2004.

cross ${ }^{\text {ref }}$

DEMING, W.E. Out of the Crisis. Cambridge, USA: Productivity Press, 1982. 
DOOLEY, K.J., FLOR, R. F. Perceptions of success and failure in TQM initiative. Journal of Quality Management, v.3, n.2, p.157-174. 1998.

cross ${ }^{\text {ref }}$

Easton, G.S. e Jarrell, S.L. The effects of total quality management on corporate performance: na empirical investigation. Journal of Business, v.71, p.253-307. 1998.

cross ${ }^{\text {ref }}$

Feigenbaum, A.V. Management of quality: the key to the nineties. Journal for Quality and Participation, v.13, n.2, p.4-19. 1990.

GOLDMAN, H.H. The origins and development of quality initiatives in American business. The TQM Magazine, v.17, n.3, p.217-226. 2005.

cross ${ }^{\text {ref }}$

HARRINGTON, H.J. Business process improvement. New York, USA: McGraw-Hill, 1991.

ISHIKAWA, K. Quality and standardization: program for economic success. Quality Progress, v.17, n.1, p.16-20. 1984.

JURAN, J.M. Managercal breakthough. New York, USA: McGraw-Hill, 1984.

. The Quality Trilogy. Quality Progress, v.19, n.8, p.19-25. 1986.

KAYNAK, H. The relationship between total quality management practices and their effects on firm performance. Journal of Operations Management, v.21, p.405-435. 2003.

cross ${ }^{\text {ref }}$

LEMAK, D.J.; REED, R. e SATISH, P.K. Commitment to total quality management: is there a relationship with firm performance? Journal of Quality Management, v.2, n.1, p.67-86. 1997.

cross ref

LIPE, M.G. e SATERIO, S.E. The balanced scorecard: judgmental effects of common and unique performance measures. The Accounting Review, v.75, n.3, p.283-298. 2000.

cross ${ }^{\text {ref }}$

MESQUITA, M. e ALLIPRANDINI, D.H. Competências essenciais para melhoria contínua da produção: estudo de caso em empresas da indústria de autopeças. Gestão e Produção, v.10, n.1, p.17-33. 2003.

cross ${ }^{\text {ref }}$

NILSSON, L.; JOHNSON, M.D. e GUSTAFSSON, A. The impact of quality practices on customer satisfaction and business results: product versus service organizations. Journal of Quality Management, v.6, n.1, p.5-27. 2001.

cross ${ }^{\text {ref }}$

PEDROZO, I.F. Gerenciamento da Rotina na administração pública - um estudo de caso na secretaria de município das finanças da Prefeitura Municipal de Santa Maria. Dissertação (Mestrado em Engenharia de Produção), Departamento de Engenharia de Produção, UFSM, Santa Maria, Brasil, 2001.

PEREZ, C.H. Estudo e prática de uma metodologia de gerenciamento da rotina num ambiente de qualidade total em uma organização de serviços. Dissertação (Mestrado em Engenharia de Produção), Departamento de Engenharia de Produção, UFSC, Florianópolis, Brasil, 1996.

REED, R.; LEMAK, D.J. e MERO, N.P. Total quality management and sustainable competitive advantage. Journal of Quality Management, v.5, n.1, p.5-26. 2000.

crossef

REGINATO, M.M. Gerenciamento da rotina e melhoria dos processos numa empresa de serviço de revelação fotográfica. Dissertação (Mestrado em Engenharia de Produção), Departamento de Engenharia de Produção. UFSM,, Santa Maria, Brasil, 1996.

REGINATO, M.M.; GODOY, L.P. e RADHARAMANAN, R. Gerenciamento da rotina em empresa prestadora de serviços - um estudo de caso. In: XVI Encontro Nacional de Engenharia de Produção (ENEGEP)/II International 
Conference on Industrial Engineering and Operations Management, Anais. Piracicaba, Brasil: Associação Braileira de Engenharia de Produção (ABEPRO)/UNIMEP, 1996. p. 8.

SALADA, M.O.d.S. O gerenciamento da rotina através do método de estabilização de processos. Dissertação (Mestrado Profissionalizante em Engenharia de Produção), Departamento de Engenharia de Produção, UFRGS, Porto Alegre, Brasil, 2002.

SAMSON, D. e TERZIOVSKI, M. The relationship between total quality management practices and operational performance. Journal of Operations Management, v.17, n.4, p.393-409. 1999.

cross ref

SCHEIBLER, R. Estruturação de um sistema de indicadores de desempenho baseado na utilização complementar do balanced scorecard e do gerenciamento da rotina do trabalho do dia-a-dia. Dissertação (Mestrado Profissionalizante em Engenharia de Produção), Departamento de Engenharia de Produção, UFRGS, Porto Alegre, Brasil, 2003.

SHETTY, Y.K. The quest for quality excellence: lessons from the Malcolm Baldridge Quality Award. SAM Advanced Management Journal, v.58, n.2, p.4-40. 1993.

SHEWHART, W.A. Economic aspects of engineering applications of statistical methods. Journal of the Franklin Institute, v.205, n.3, p.163-186. 1928.

cross ${ }^{\text {ref }}$ (Statistics)

. Application of statistical methods to manufacturing problems. Bell telephone laboratories, inc, 1938. 24 p.

THIAGARAJAN, T. e ZAIRI, M. An empirical analysis of critical factors of TQM: A proposed tool for self-assessment and benchmarking purposes. Benchmarking for quality management \& technology, v.5, n.4, p.291-303. 1998.

WAAL, A.A.A.d. Behavioral factors important for the successful implementation and use of performance management systems. Management Decision, v.41, n.8, p.688-697. 2003.

cross ${ }^{\text {ref }}$

\section{DADOS DOS AUTORES:}

Nome completo: Priscila Nogueira

Filiação institucional: UFF

Departamento: Mestrado em Sistemas de Gestão

Função ou cargo ocupado: Discente

Endereço completo para correspondência (Rua Passos da Pátria, 156, São Domingos, Niterói, RJ,

Brasil e 24.220-045):

Telefones para contato:

e-mail:pnogueira@sustentabile.com.br

Nome completo: Helder Gomes Costa

Filiação institucional: UFF

Departamento: Departamento de Engenharia de Produção

Função ou cargo ocupado: Professor Associado 2

Endereço completo para correspondência (Rua Passos da Pátria, 156, São Domingos, Niterói, RJ, 
Brasil e 24.220-045):

Telefones para contato: (21) 262975888922297

e-mail:.hgc@pq.cnpq.br

Recebido para publicação em: 27/08/2009

Aceito para publicação em: 01/12/2009 